\title{
Protein Surface Printer for Exploring Protein Domains
}

\author{
Yang Li, ${ }^{\dagger}$ Baofu Qiao, ${ }^{*, \ddagger}$ and Monica Olvera de la Cruz ${ }^{*,+,}, \mathbf{9}, \dagger$ \\ $\dagger$ Department of Chemical Engineering, Northwestern University, Evanston, Illinois 60201, \\ United States \\ $\ddagger$ Department of Material Science and Engineering, Northwestern University, Evanston, \\ Illinois 60201, United States \\ 9Department of Chemistry, Northwestern University, Evanston, Illinois 60201, United \\ States
}

E-mail: qiaobf@northwestern.edu; m-olvera@northwestern.edu

Phone: +1-847-491-7801 


\section{S1. PETase trajectory alignment and multiframe analysis}

Table S1: Surface domains of PETase

\begin{tabular}{ccccc}
\hline $\begin{array}{c}\text { Software } \\
\text { Force field }\end{array}$ & Positively charged & Negatively charged & Polar Neutral & Non polar \\
\hline $\begin{array}{c}\text { GROMACS } \\
\text { CHARMM36m }\end{array}$ & $6.2 \% \pm 0.5 \%$ & $4.9 \% \pm 0.5 \%$ & $61.0 \% \pm 0.8 \%$ & $27.9 \% \pm 1.0 \%$ \\
$\begin{array}{c}\text { NAMD } \\
\text { CHARMM36 }\end{array}$ & $6.3 \% \pm 0.5 \%$ & $4.9 \% \pm 0.4 \%$ & $61.2 \% \pm 1.1 \%$ & $27.6 \% \pm 1.0 \%$ \\
$\begin{array}{c}\text { AMBER } \\
\text { AMBER14SB }\end{array}$ & $6.4 \% \pm 0.6 \%$ & $4.9 \% \pm 0.5 \%$ & $60.3 \% \pm 1.3 \%$ & $28.3 \% \pm 1.1 \%$ \\
$\begin{array}{c}\text { OpenMM } \\
\text { AMOEBA 13 }\end{array}$ & $6.0 \% \pm 0.5 \%$ & $5.2 \% \pm 0.4 \%$ & $60.7 \% \pm 1.0 \%$ & $28.0 \% \pm 1.0 \%$ \\
\hline
\end{tabular}

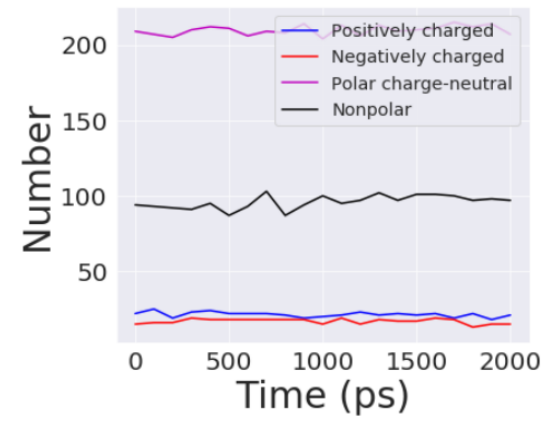

(a)

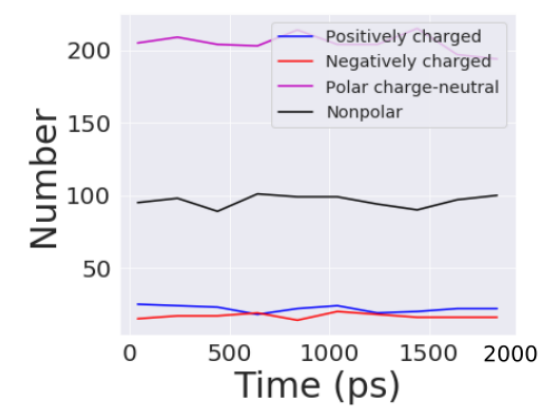

(c)

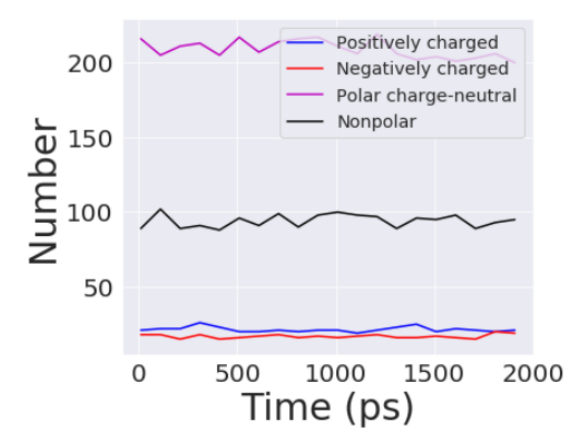

(b)

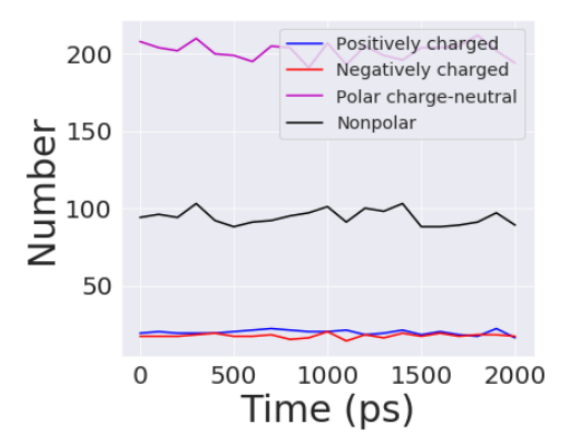

(d)

Fig. S1: Percentage of surface domains change over time. Color legends are shown in figures. (a) Gromacs/CHARMM36m (b) NAMD/CHARMM36 (c) AMBER/AMBER14SB (d) OpenMM/AMEOBA 13 


\section{S2. P450 dimer single frame analysis}

Table S2: Surface domains of P450 dimer

\begin{tabular}{cccc}
\hline Positively charged & Negatively charged & Polar Neutral & Non polar \\
\hline $14.9 \%$ & $19.1 \%$ & $30.7 \%$ & $35.3 \%$ \\
\hline
\end{tabular}




\section{S3. Case study: SARS-CoV-2 and SARS-CoV analysis}

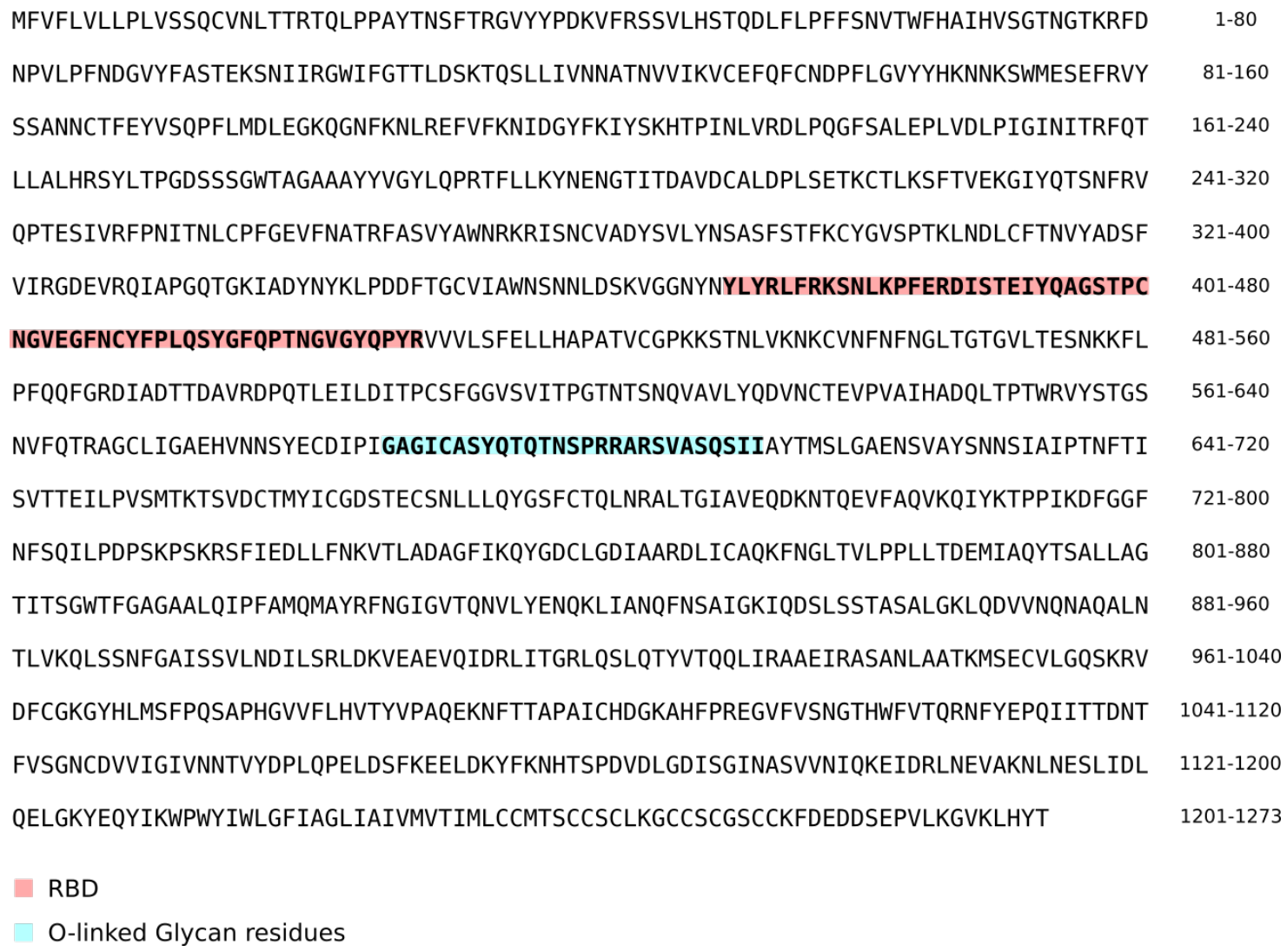

Fig. S2: The sequence of SARS-CoV-2 spike protein. 


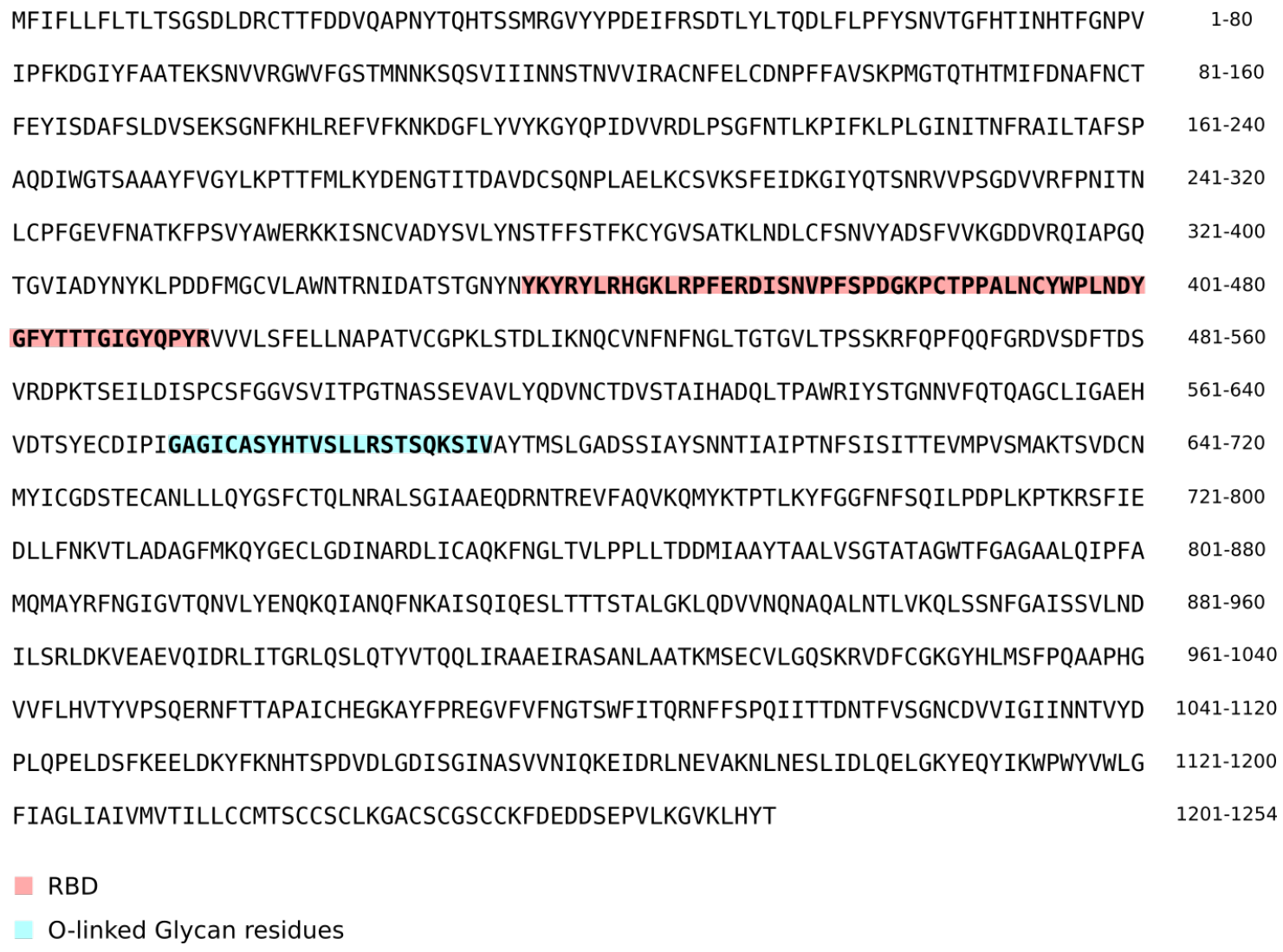

Fig. S3: The sequence of SARS-CoV spike protein.

Table S3: Surface domains of the spike protein.

\begin{tabular}{ccccc}
\hline Virus & Positively charged & Negatively charged & Polar Neutral & Non polar \\
\hline SARS-CoV-2 & $9.0 \%$ & $10.4 \%$ & $47.2 \%$ & $33.4 \%$ \\
SARS-CoV & $9.2 \%$ & $11.0 \%$ & $45.5 \%$ & $34.3 \%$ \\
\hline
\end{tabular}

Table S4: Surface domains of RBD.

\begin{tabular}{ccccc}
\hline Virus & Positively charged & Negatively charged & Polar Neutral & Non polar \\
\hline SARS-CoV-2 & $10.3 \%$ & $7.4 \%$ & $50.0 \%$ & $32.3 \%$ \\
SARS-CoV & $17.2 \%$ & $8.6 \%$ & $39.0 \%$ & $35.2 \%$ \\
\hline
\end{tabular}

Table S5: Surface domains of ACE2.

\begin{tabular}{lcccc}
\hline & Positively charged & Negatively charged & Polar Neutral & Non polar \\
\hline Outer Surface & $9.8 \%$ & $19.4 \%$ & $37.2 \%$ & $33.6 \%$ \\
Inner Surface & $13.1 \%$ & $16.8 \%$ & $45.3 \%$ & $24.8 \%$ \\
\hline
\end{tabular}




\section{S4. 3D printout of each analysis}

Movie S1: 3D printout of PETase surface from Gromacs

Movie S2: 3D printout of PETase surface from NAMD

Movie S3: 3D printout of PETase surface from AMBER

Movie S4: 3D printout of PETase surface from OpenMM

Movie S5: 3D printout of SARS-CoV-2 spike protein surface

Movie S6: 3D printout of SARS-CoV spike protein surface

Movie S7: 3D printout of SARS-CoV-2 RBD

Movie S8: 3D printout of SARS-CoV RBD

Movie S9: 3D printout of ACE2 surface

Movie S10: 3D printout of SARS-CoV-2 O-linked residues

Movie S11: 3D printout of SARS-CoV O-linked residues 